\title{
Peningkatan Kesadaran Masyarakat Terhadap Penyakit Hipertensi dan Gout di Kelurahan Pakuan Baru
}

\author{
Deny Sutrisno ${ }^{1}$ Rena Okmadini ${ }^{* 2,}$ Neneng Zulmaidha Ihsan ${ }^{3,}$ Unra Mahari Putra ${ }^{4}$, Fery Lidiya \\ Assiya $^{5}$, Loly Juliani ${ }^{6}$, Cyndi Snaini ${ }^{7}$, Shania Sirait ${ }^{8}$, Tia Meilita ${ }^{9}$, Yola Pramita ${ }^{10}$, Tiwi Jaya \\ mariana $^{11}$ \\ 1,2,3,4,5,6,7,8,9,10,11 Program Studi Farmasi, Sekolah Tinggi Ilmu Kesehatan Harapan Ibu Jambi \\ E-mail: 1denysutrisno@gmail.com, ${ }^{* 2}$ renaokmadini17@gmail.com, \\ ${ }^{3}$ zulmaidhaihsanneneng@gmail.com, ${ }^{4}$ unra.mahari.putra@gmail.com, \\ ${ }^{5}$ lidiyaassyifaa@gmail.com, ${ }^{6}$ lolyjuliani28@gmail.com, ${ }^{7}$ cindyaa500@gmail.com, \\ 8shaniatryanas@gmail.com, ${ }^{9}$ tiameilita47@gmail.com, ${ }^{10}$ yolapramita04@gmail.com, \\ ${ }^{11}$ wtungkir@gmail.com
}

\begin{abstract}
Abstrak
Penyakit tidak menular (PTM) merupakan penyakit yang bersifat kronis dan tidak ditularkan dari orang keorang. PTM terus mengalami peningkatan seiring dengan perubahan pola hidup masyarakat kearah yang kurang seimbang. Faktor resiko PTM di Provinsi Jambi khususnya di RT. 22 Kelurahan Pakuan Baru Kecamatan Jambi Selatan antara lain Nasofaringitis Akut, Hipertensi dan Asam Urat. Hal tersebut disebabkan kurangnya pengetahuan dan kesadaran terhadap bahaya PTM yang menyebabkan deteksi dini. Hal ini juga disebabkan enggannya masyarakat memeriksakan diri selama sebelum merasa sakit. Masalah inilah yang menjadi dasar dilakukannya kegiatan pengabdian berupa pemeriksaan kesehatan secara gratis yang diselingi dengan diskusi seputar kesehatan, khusunya PTM dan kiat-kiat dalam pencegahannya.
\end{abstract}

Kata kunci: Penyakit tidak menular, Hipertensi, Asam Urat

\section{Abstract}

Non-communicable disease (PTM) is a chronic disease and is not transmitted from person to person. PTM continues to increase along with changes in people's lifestyle towards an unbalanced direction. Risk factors for PTM in Jambi Province, especially in RT. 22 Pakuan Baru Village, South Jambi District, among others, are acute nasopharyngitis, hypertension and gout. This is due to a lack of knowledge and awareness of the dangers of PTM which leads to early detection. This is also due to the reluctance of the public to get checked out before feeling sick. This problem is the basis for carrying out service activities in the form of free health checks interspersed with discussions about health, especially PTM and tips in prevention.

Keywords: Non-communicable disease, Hypertension, Uric Acid.

\section{PENDAHULUAN}

Kehidupan di masa sekarang dengan kemajuan Teknologi di negara berkembang mengakibatkan transisi demografi dan epidemiologi yang ditandai dengan perubahan gaya hidup yang tidak sehat sehingga timbulnya penyakit yang menular maupun tidak menular [1]. Saat ini banyak sekali penyakit yang bisa timbul diakibatkan dari gaya hidup masyarakat yang tidak sehat. Penyakit yang umumnya terjadi yakni hipertensi, asam urat, diabetes serta penyakit maag, penyakit tersebut timbul disebabkan dari faktor hidup atau pola makan yang tidak sehat. 
Dimana sekarang ini banyak sekali makanan cepat saji yang membuat kita tergiur akan makanan tersebut. Bukan karna rasa yang enak tapi karna proses penyajian nya yang sangat praktis.

Salah satu penyakit yang bisa disebabkan oleh faktor gaya hidup yakni hipertensi. Hipertensi merupakan suatu keadaan dimana terjadinya peningkatan tekanan darah sistolik $\geq$ $140 \mathrm{mmHg}$ dan diastolic $\geq 90 \mathrm{mmHg}$ setelah dilakukan pemeriksaan dua kali pengukuran secara terpisah [2]. Penyakit asam urat atau dalam dunia medis disebut penyakit pirai atau penyakit gout (arthritis gout) adalah penyakit sendi yang disebabkan oleh tingginya asam urat didalam darah. Kadar asam urat yang tinggi di dalam darah atau melebihi batas normal dapat menyebabkan penumpukan asam urat didalam persendian dan organ tubuh lainnya. Penumpukan asam urat inilah yang membuat sendi sakit, nyeri, memerah dan meradang [3]. Asam urat juga bisa disebabkan dari pola makan yang tidak sehat, seperti terlalu banyak mengkonsumsi makanan yang mengandung purin tinggi.

Kegiatan ini bertujuan untuk meningkatkan pengetahuan dan kesadaran masyarakat mengenai pentingya mengatur pola hidup untuk menurunkan risiko terjadinya penyakit yang tidak menular di lingkungan Pakuan Baru RT 22.

\section{METODE}

Kegiatan pengabdian masyarakat ini dilaksanakan pada tanggal 6 maret-27 maret 2021 di Kelurahan Pakuan Baru RT. 22 Kecamatan Jambi Selatan, Kota Jambi. Kegiatan ini dilakukan oleh dosen dan mahasiswa Sekolah Tinggi Harapan Ibu Jambi. Metode yang digunakan dalam kegiatan ini yakni yang pertama melakukan pre-test, kedua mengadakan sosialisasi terkait hipertensi, dan asam urat kemudian tahap ketiga yaitu mengadakan Post-test kepada warga.

\subsection{Tahap pertama}

Melakukan Pre-test untuk mengukur tingkat pengetahuan awal masyarakat mengenai kesehatan terkait hipertensi dan asam urat. Instrument pengukurannya adalah soal-soal mengenai hipertensi dan asam urat.

\subsection{Tahap kedua}

Penyuluhan kepada warga mengenai penyakit hipertensi dan asam urat kepada warga. Bahan yang disiapkan yaitu leaflet terkait penyakit hipertensi dan asam urat serta lembar kuisioner. Selain itu juga dilakukan tes kesehatan untuk masyarakat RT 22 Kelurahan Pakuan Baru.

\subsection{Tahap ketiga}

Kegiatan Post-test dilakukan setelah melakukan penyuluhan untuk mengetahui adakah perubahan atau peningkatan nilai rata-rata pengetahuan setelah diadakan penyuluhan. Instrument yang digunakan sama dengan instrument pada tahap pertama.

\section{HASIL DAN PEMBAHASAN}

\subsection{Tahap pertama}

Melakukan Pre-test, kegiatan Pre-test ini bertujuan untuk mengukur tingkat pengetahuan masyarakat mengenai kesehatan terkait hipertensi dan asam urat. Kegiatan Pre-test ini dilakukan sebelum penyuluhan dimulai guna mengetahui sejauh mana pengetahuan masyarkat sebelum dilakukan penyuluhan. Media yang digunakan dalam pre-test ini adalah kertas yang berisi pertanyaan-pertanyaan terkait kesehatan yang akan dibahas dalam penyuluhan yang nantinya akan dinilai. 
Pre-test atau tes awal yaitu tes yang dilaksanakan dengan tujuan untuk mengetahui sejauh manakah pengetahuan materi atau bahan pelajaran yang akan diajarkan [4]. Sedangkan Post-test adalah tes yang dilaksanakan setelah proses penyuluhan atau pembelajaran dengan tujuan untuk mengetahui apakah semua materi yang sudah disampaikan dapat dipahami [4].

\subsection{Tahap kedua}

Kegiatan edukasi yaitu melakukan penyuluhan kepada warga mengenai penyakit hipertensi dan asam urat kepada warga. Terkait gejala-gejala penyakit, proses pencegahan dan pengobatan.

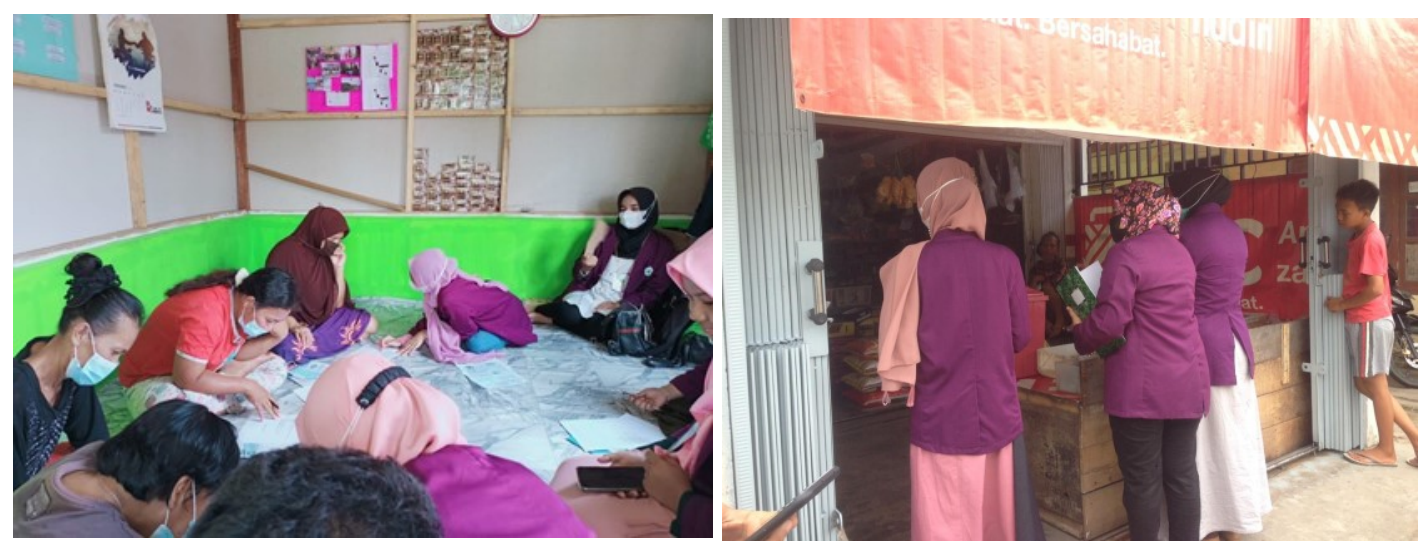

Gambar 1. Penyuluhan Kesehatan

Selain penyuluhan juga dilakukan pemeriksaan kesehatan. Pemeriksaan kesehatan yang diadakan dihalaman pos kamling RT 22 Kelurahan Pakuan Baru yang dihadiri sekitar 15 orang. Kegiatan bertujuan memberikan pengecekan kesehatan secara gratis kepada warga RT 22 dan sedikit memberikan informasi dan masukan mengenai kesehatan baik hipertensi, asam urat dan diabetes. Dimana dari hasil pemeriksaan dapat dilihat pada gambar 2.

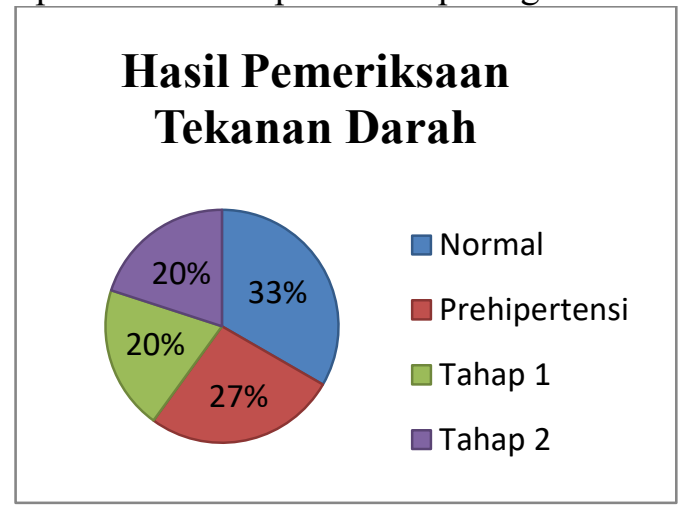

Gambar 2. Grafik Hasil Pemeriksaan Tekanan darah

Berdasarkan dari hasil pemeriksaan tekanan darah pada warga RT. 22 kebanyakan mengalami hipertensi baik prehipertensi, hipertensi tahap 1 maupun hipertensi tahap 2. Dari rata-rata hasil pemeriksaan tekanan darah warga yaitu 142/86 $\mathrm{mmHg}$ termasuk kedalam kategori prehipertensi. Hipertensi adalah penyakit tekanan darah yang tinggi dan menetap dengan keadaan dimana tekanan darah sistolik $>140 \mathrm{mmHg}$ dan diastolik $>90 \mathrm{mmHg}$ dalam pengukuran berulang [1] [5]. Penyakit hipertensi dapat meningkatkan resiko terjadinya penyakit kardiovaskular dengan adanya peningkatan sistolik sekitar $20 \mathrm{mmHg}$ dan peningkatan diastlolik $10 \mathrm{mmHg}$ [6]. Pencegahan yang dapat dilakukan yakni mengatur pola makan, hidup sehat, kurangi berat badan, tidak mengkonsumsi daging, menghindari alkohol dan juga stres [7]. 


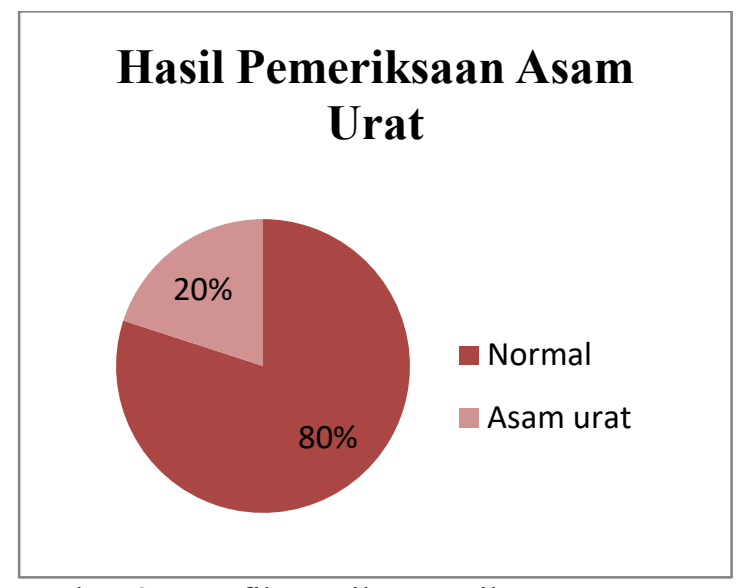

Gambar 3. Grafik Hasil Pemeriksaan Asam Urat

Dari hasil pemeriksaan Asam urat warga RT. 22 didapatkan hasil 80\% normal yang artinya tidak menderita asam urat hasil pemeriksaan rata-rata kadar asam urat pada wanita sekitar $6.4 \mathrm{mg} / \mathrm{dl}$ sedangkan pada pria $5.4 \mathrm{mg} / \mathrm{dl}$, dari hasil pemeriksaan dapat disimpulkan bahwa penderita asam urat banyak dialami pada wanita dibandingkan pria. Dimana kadar asam urat normal dalam darah pria dewasa ialah $3.5-7.2 \mathrm{mg} / \mathrm{dl}$ sedangkan pada wanita $2.6-6.0 \mathrm{mg} / \mathrm{dl}$ [8]. Penyakit asam urat adalah penyakit yang disebabkan oleh penumpukan Kristal pada persendian yang menyebabkan sakit pada bagian sendi [9]. Penyakit gout atau asam urat biasanya disebabkan oleh factor genetik, lingkungan serta makanan yang banyak mengandung purin [10]. Pencegahan yang dapat dilakukan untuk mengatasi asam urat khususny pada lansia yang biasanya banyak menderita asam urat yakni membatasi makanan khususny makanan yang tinggi purin, kacang-kacangan dan lebih menjaga kesehatan serta rutin berolahraga dan istirahat yang cukup [11].

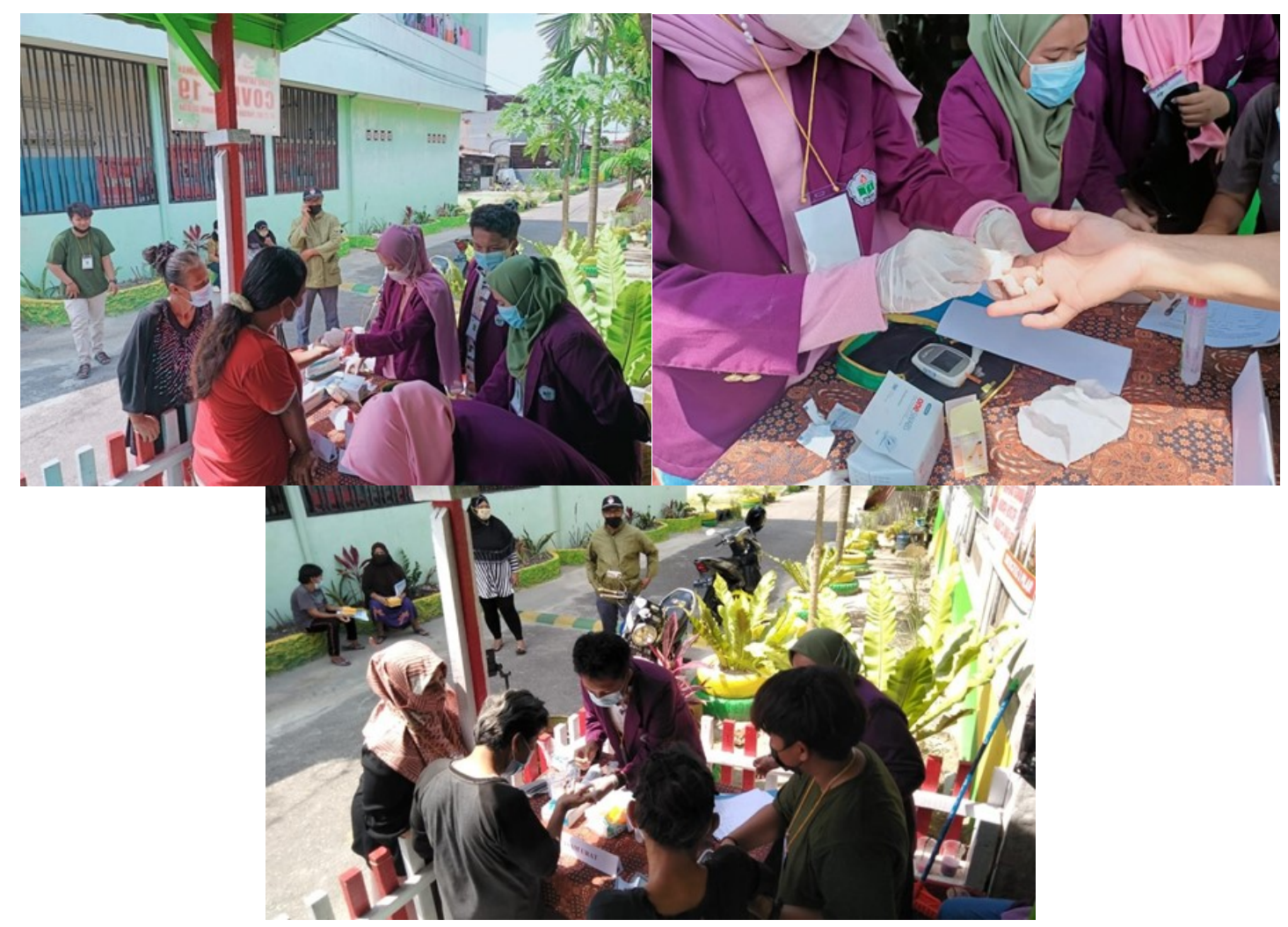

Gambar 4. Pengecekan Hipertensi dan Asam Urat 


\subsection{Tahap ketiga}

Kegiatan Post-test dilakukan setelah melakukan penyuluhan untuk mengetahui adakah perubahan pengetahuan setelah diadakan penyuluhan. Hasil skor Post-test yang dilakukan ratarata skornya 92.72

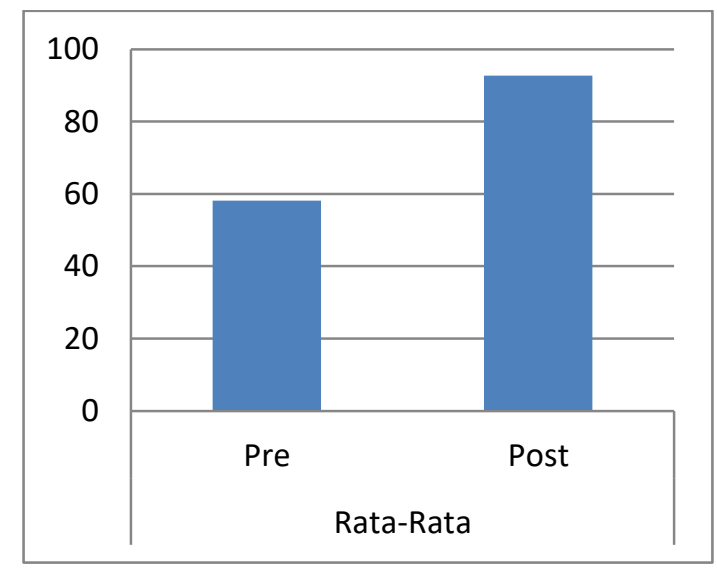

Gambar 5. Grafik Nilai Pre tes dan posttest Penyuluhan Kesehatan

\section{KESIMPULAN DAN SARAN}

Kegiatan Pengabdian Masyarkat yang dilakukan Sekolah Tinggi Ilmu Kesehatan Harapan Ibu Jambi di RT. 22 Kelurahan Pakuan Baru, Kecamatan jambi selatan, Kota Jambi mendapatkan respon postif dari Masyarakat warga RT. 22. Kegiatan penyuluhan ini meningkatkan pengetahuan terhadap warga RT. 22 terkait Kesehatan. Diharapkan masyarakat untuk mau dan mampu menerapkan pola hidup bersih dan sehat, mengecek kesehatan secara berkala, mengatur pola makan, memanfaatkan sumber daya alam yang ada disekitar dan aktif dalam kegiatan yang dilaksanakan oleh instansi dalam proses peningkatan taraf hidup maupun kegiatan lainnya.

\section{DAFTAR PUSTAKA}

[1] A. Yonata and A. S. P. Pratama, "Hipertensi sebagai Faktor Pencetus Terjadinya Stroke," J. Major., vol. 5, no. 3, pp. 17-21, 2016.

[2] B. Nuraini, "Risk Factors of Hypertension," J Major., vol. 4, no. 5, pp. 10-19, 2015.

[3] Nurhamidah and S. Nofiani, "Faktor-Faktor Yang Berhubungan Dengan Kejadian Asam Urat Pada Pasien Rawat Jalan Di Rumah Sakit Stroke Nasional Bukittinggi Tahun 2015," Fakt. Yang Berhubungan Dengan Kejadian Asam Urat Pada Pasien Rawat Jalan Di Rumah Sakit Stroke Nas. Bukittinggi Tahun 2015, no. 1, p. 2, 2015.

[4] I. Effendy, "Pengaruh Pemberian Pre-Test dan Post-Test Terhadap Hasil Belajar Mata Diklat HDW.DEV.100.2.a pada Siswa SMK Negeri 2 Lubuk Basung," J. Ilm. Pendidik., vol. 1, no. 2, pp. 81-88, 2016.

[5] E. K. R. Sudarsono, J. F. A. Sasmita, A. B. Handyasto, N. Kuswantiningsih, and S. S. Arissaputra, "Peningkatan Pengetahuan Terkait Hipertensi Guna Perbaikan Tekanan Darah pada Pemuda di Dusun Japanan, Margodadi, Seyegan, Sleman, Yogyakarta," J. Pengabdi. Kpd. Masy. (Indonesian J. Community Engag., vol. 3, no. 1, pp. 26-38, 2017, doi: $10.22146 / \mathrm{jpkm} .25944$.

[6] S. Iswahyuni, "Hubungan Antara Aktifitas Fisik Dan Hipertensi Pada Lansia," Profesi (Profesional Islam. Media Publ. Penelit., vol. 14, no. 2, p. 1, 2017, doi: 
10.26576/profesi.155.

[7] E. Suprayitno and N. Huzaimah, "Pendampingan Lansia Dalam Pencegahan Komplikasi Hipertensi," SELAPARANG J. Pengabdi. Masy. Berkemajuan, vol. 4, no. 1, p. 518, 2020, doi: 10.31764/jpmb.v4i1.3001.

[8] Arjani, "Gambaran Kadar Asam Urat dan Tingkat Pengetahuan Lansia di Desa Samsam Kecamatan Kerambitan Kabupaten Tabanan," Zprav. Československého sdružení uživatelů TeXu, vol. 2, no. 3, pp. 137-141, 2018, doi: 10.5300/1992-3/137.

[9] S. Widya et al., "Hubungan Pola Makan Dengan Terjadinya Penyakit Gout (Asam Urat) Di Desa Limran Kelurahan Pantoloan Boya Kecamatan Taweli," Kesmas, vol. 7, no. 6, 2018.

[10] F. I. Boleu, J. C. Mangimbulude, and F. F. Karwur, "Hyperurisemia Dan Hubungan Antara Asam Urat Darah Dengan Gula Darah Sewaktu Dan Imt Pada Komunitas Etnik Asli Di Halmahera Utara," J. Ilmu Kesehat. Masy., vol. 9, no. 2, pp. 96-106, 2018, doi: 10.26553/jikm.2018.9.2.96-106.

[11] F. Ardhiatma, "Hubungan Antara Pengetahuan Tentang Gout Arthitis Terhadap Perilaku Pencegahan gout Arthitis Pada Lansia," Glob. Heal. Sci., vol. 2, no. 2, pp. 111-116, 2017. 